\title{
Childhood Obesity: Epidemiology, Determinants, and Prevention
}

\section{Mohamed SM*}

Department of Applied Nutrition, Faculty of Livestock, Fisheries and Nutrition, Wayamba University of Sri Lanka, Makandura, Gonawila (NWP), Sri Lanka

\begin{abstract}
Recently, high prevalence of overweight and obesity has been reported in children and adolescents both in developed and in developing countries and these figures have been projected to increase further in coming years. Childhood obesity increases the risk of adulthood obesity and obesity related diseases such as hypertension, diabetes mellitus, and dyslipidemia. Several studies highlight recent evidence regarding the role of genetics, age, gender, birth weight, dietary pattern: eating fast foods and snacks and skipping breakfast and behavioral characteristics: sedentary activities, physical activity pattern, and sleeping hours related to occurrence of obesity in children and adolescents. Interventions related to changing dietary practices and maintenance of regular physical activity among children through parental initiative and social support in natural settings such as at home and in schools, or afterschool care services are the most important to prevent childhood obesity.
\end{abstract}

Keywords: Obesity; Children; Determinants; Prevention; Genetics; Physical activity; Dietary pattern

\section{Introduction}

Childhood obesity is one of the most serious public health challenges of the 21 st century. The prevalence of obesity is increasing both in developed and in developing countries and has become a major public health problem. Up to the 1980s developing countries were with the lowest rates, but since then overweight and obesity prevalence have gradually increased in children. The global prevalence of overweight and obesity in children aged $5-17$ years is $10 \%$ and this global average covers a wide range of prevalence levels in different regions and countries with above 30\% in America and below 2\% in Sub Saharan Africa [1]. Further, projections to the year 2010 for estimated prevalence of overweight and obesity in school age children (aged $5-17$ years) are with $46 \%$ in America and below 5\% in Africa [2] .

For children, between 5-17 years in this regional prevalence data on overweight and obesity are currently unavailable [3]. However, data for overweight and obesity prevalence among children in different countries in South Asia are available: $25.0 \%$ among children from 2 to 15 years in Bangladesh and 22.0\% among children from 5 to 19 years in India. Moreover, secular trends indicate increasing prevalence rates in these countries: for example, 9.8 to $11.7 \%$ among children from 5 to 19 years in India during 2006-2009 [4,5].

In recent years, the increase in the prevalence of obesity has led this condition to the forefront of the public health in Sri Lanka, especially among children. The overweight and obesity prevalence among children in Sri Lanka shows different ranges with provincial and gender variations; among boys and girls between 8 and 10 years this was $4.3 \%$ and $3.1 \%$ respectively and obesity prevalence among primary school children in Colombo district is 5.1\%in 2008 [6-8].

Obesity is a condition of abnormal or excess fat accumulation in adipose tissue, which may adversely affect health of body and increases health problems. Although the mechanism of obesity development is not fully understood, it is confirmed that obesity occurs when energy intake exceeds energy expenditure $[9,10]$.

The normal growth of adipose tissue takes account of several phases. During first year (early infancy) of the first period, adiposity increases and it reduces in next year and remains stable for several years. Adiposity rebound start at around 6 years during second period. From this stage, both size and number of adipocytes increases $[11,12]$.
Therefore, childhood is the critical period to develop obesity because of the adiposity rebound.

Obesity negatively influences a child's self-esteem and results in diminished quality of life. Moreover, children with high body mass index (BMI) often become obese adults, who are at increased risk of developing obesity-related diseases, such as type 2 diabetes, hypertension, dyslipidemia and certain types of cancer and place significant financial burden on healthcare systems $[12,13]$.

For measuring healthy body weight, it is difficult to develop one simple index for overweight and obesity in children and adolescents because their bodies undergo a number of physiological changes as they grow.

Depending on the age, there are different methods to measure a body's healthy weight:

- For children aged 0-5 years

The WHO Child Growth Standards, launched in April 2006, include measures for overweight and obesity for infants and young children up to age 5 [14].

\section{- For individuals aged 5-19 years}

World Health Organization (WHO) developed the Growth Reference Data for 5-19 years. It is a reconstruction of the 1977 National Center for Health Statistics (NCHS)/WHO reference and uses the original NCHS data set supplemented with data from the WHO child growth standards sample for young children up to age 5 [15].

\section{Determinants of Childhood Overweight/Obesity}

A number of studies indicate that several key determinants are widely acknowledged as the main drivers of the obesity epidemic among children.

*Corresponding author: Mohamed SM, Department of Applied Nutrition, Faculty of Livestock, Fisheries and Nutrition, Wayamba University of Sri Lanka, Makandura Gonawila (NWP), Sri Lanka, E-mail: mushisharif22@gmail.com

Received March 13, 2015; Accepted April 09, 2015; Published April 15, 2015

Citation: Mohamed SM (2015) Childhood Obesity: Epidemiology, Determinants, and Prevention. J Nutr Disorders Ther 5: 156. doi:10.4172/2161-0509.1000156

Copyright: ( 2015 Mohamed SM. This is an open-access article distributed under the terms of the Creative Commons Attribution License, which permits unrestricted use, distribution, and reproduction in any medium, provided the original author and source are credited. 


\section{Genetics}

Obesity tracks in families, and one of the strongest predictors of child overweight is the BMI of the mother and father. In recent years, progress was made in identifying genes that may contribute to this effect. A recent study showed for association with the FTO (fat mass and obesity-associated) gene and found strong associations with BMI and weight among children. Moreover, a defect in the melanocortin 4 receptor gene (MC4R) is associated with a severe and early form of monogenic obesity in children [16].

\section{Age and gender}

Age and gender have been identified as key determinants for the development of obesity. A study conducted among 2-18 children in Nigeria and revealed that Males had higher BMI than females at age group 2-6 years, whereas females had higher BMI than males at age groups 11-14 years and 15-18 years [17].

A study conducted among Sri Lankan children age between 5 and 14 found that fat free mass index (fat free mass/height ${ }^{2}$ ) was decreased from age 5 to 6 and after that adipose tissue was increased without much increment in fat free mass index. After that fat mass index (fat mass/ height ${ }^{2}$ ) remained relatively stable and fat free mass index increased a little for girls. However, adiposity was increased until 10 years of age and fat free mass index was also increased a little for boys [18]. It clearly showed that weight gain in Sri Lankan children is due to increase in adiposity rather than increase in non-fat tissue (Figure 1).

\section{Birth weight}

Rapid weight gain which was traditionally considered as a healthy intervention for low birth weight infants is now recognized as a potential risk factor of increasing interest for obesity; In the geographically defined birth cohort of the Avon longitudinal study of pregnancy and childhood (ALSPAC), it showed that early postnatal catch-up growth, between birth and two years, is a risk factor for childhood obesity and may therefore contribute to the greatest risk for disease in adulthood [19].

\section{Dietary pattern}

Eating fast foods and snacks: Fast foods play as a key contributor

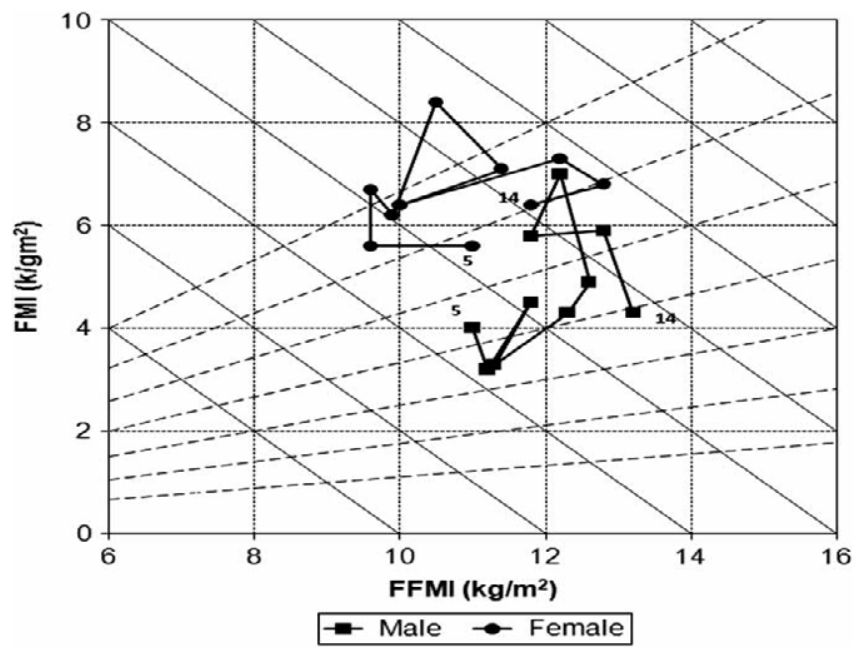

Figure 1: mean fat mass index and fat free mass index of 5-14 year old Sri Lankan children. to the rising prevalence of obesity among children because of fast food's poor nutritional quality, as fast foods have higher total energy, total fat, and saturated fat intakes; have refined carbohydrates and lower fiber intakes; and with higher energy density [20,21]. Further, fast food consumption is also associated with higher intake of sugarsweetened beverages and French fries and lower intake of milk, fruit, and vegetables $[22,23]$.

Skipping breakfast: Breakfast is a most important meal to start a day. Skipping breakfast leads to hunger and increases the amount of lunch. Therefore, it leads to play a key role in causing obesity in children [24]. Some studies showed the higher prevalence among students who skip breakfast than others $[25,26]$. Ortega et al., identified through 7 day food records that obese subject omit breakfast than normal person. It suggests that inadequate food choices contribute to poor food choices for rest of the day and it increases the risk of obesity in long term [27].

\section{Behavioral Characteristics}

\section{Sedentary activities and screen viewing}

Rapid increase in childhood obesity has also been attributed to a shift in the activity patterns from outdoor play to indoor entertainment: television viewing, internet, and computer games. A study suggested that decreasing any type of sedentary time is associated with lower health risk in youth aged 5-17 years. In particular, the evidence suggested that daily TV viewing in excess of 2 hours is associated upward in BMI [28,29]. Another study showed that Overweight and obese children were more sedentary and higher screen time than normal weight children [30]. Further, a European youth heart study conducted among 9-10 year old boys and girls found the significant positive relationships between TV viewing and adiposity after adjusting for gender, age group, study location, sexual maturity and birth weight [31]. Mitchell et al. studied the association of hours of objectively measured sedentary behavior and odds of being obese and confirmed that sedentary behavior was positively associated with obesity.

\section{Physical activity pattern}

Physical activity plays an important role in protection from obesity. A study revealed that Prevalence of overweight and obese was higher among children who travel to school in motor vehicle than children who travel by cycle or walk [32]. Another study done in Iran reported significant difference in physical activity among obese and non-obese children. Non-obese children engaged with more physical activities like running, football, and travel to school by foot than obese children did [33]. A study conducted in Bangladesh reported that physical activity more than 30 minutes have protective effect on obesity in 10-15 year old school children [28].

\section{Sleeping hours}

In school-age children, several studies have consistently reported that short sleep duration was an independent risk factor for obesity [34]. A cross-sectional study conducted among 229 Mexican American 8-10-year-olds and concluded that children who slept less were more likely to have a higher BMI Z-Score [35]. A cohort study done in Japan observed positive relationship between decreased sleeping hours and obesity after adjusting for potential confounding factors [36].

\section{Strategies for Childhood Obesity Prevention}

Obesity prevention is not simply an issue of individual responsibility and prevention strategies seem to be more effective in children than in adults. Therefore, Successful strategies for obesity prevention among 
children should be targeted and implemented in natural settings for influencing the diet and physical activities at home, in preschool institutions, schools, or after-school care services.

\section{School-Based Strategies}

School-based programs have great opportunity to promote healthy nutrition and physical activity because most children attend school and a child spends more than half of his/her waking hours at school on any given school day. Therefore, following school-based interventions should be implemented as standard practice in educational settings improvements in knowledge, attitudes, and behavior:

- Components on healthy eating, physical activity and body image should be integrated into the regular curriculum.

- Sessions for physical activity and the development of fundamental movement skills should be included throughout the school week.

- The nutritional quality of foods made available to students (e.g. in school canteens) should be closely monitored and improved.

- An environment and culture should be created that supports children eating nutritious foods and being active throughout each day.

- Parents should be engaged to support activities in the home setting to encourage children to become more active, eat more nutritious foods and spend less time in screen-based activities.

\section{Home-Based Strategies}

Parental initiative is necessary to succeed the home-based strategies influencing the diet and physical activity among children. Therefore, parents should be aware about following activities:

- Should be good role models.

- Should encourage the children to have regular meals including breakfast at home, because children who take part in family meals are also more likely to eat fruits, vegetables, and grains and less likely to snack on unhealthy foods.

- Should provide the children with healthy food choices.

- Should encourage young children to develop good eating habits and preferences for healthy foods because eating behaviors that develop during childhood tend to track into adulthood.

- Should accompany children to nearby parks and play with them. This would not only add to their health benefits but also let them supervise their children. Further, it helps to limit sedentary activities.

- Should involve the children in food purchasing by taking children to food shopping and allowing them to select healthy foods [37-39].

\section{Conclusion}

Childhood obesity leads to its related non-communicable diseases and psychosocial health problems in children. This is because Childhood obesity is a crucial issue that needs to be addressed urgently. Changing dietary practices and maintenance of regular physical activity starting as early as infancy through parental initiative and social support interventions are the most important strategies to tackle childhood obesity.

\section{References}

1. Lasserre M, Arnald C, Pacaud P, Pascal B (2007) Worldwide trends in childhood obesity. Swiss Med Wkl 137: 157-158.

2. Wang $Y$, Lobstein $T$ (2006) Worldwide trends in childhood overweight and obesity. International Journal of Pediatric Obesity 1: 11-25.

3. deWlide JA, Zandbergen-Harlaar S, van Buuren S, Middlekoop BJ (2013) Trends in body mass index distribution and prevalence of thinness, overweight and obesity in two cohorts of Surinamese South Asian children in The Netherlands. Arch Dis Child 98: 280-285.

4. Bulbul T, Houque M (2014) Prevalence of childhood obesity and overweight in Bangladesh: findings from a countrywide epidemiological study. BMC Pediatrics 14: 86.

5. Guptha N, Goel K, Shah P, Mishra A (2012) Childhood Obesity in Developing Countries: Epidemiology, Determinants, and Prevention. Endocrine Reviews 33: 48-70.

6. Thilakarathne RMLR, Wijesinghe DGNG (2011) Association between Nutritional Status and Life Style Practices of Primary School Children in the Colombo District: A Pilot Study. Tropical Agricultural Research 22: 392-401.

7. Wickramasinghe VP, Lamabadusuriya SP, Atapattu N, Sathyadas G Karuparanantha S, et al. (2004) Nutritional status of school children in an urban area of Sri Lanka. Ceylon Medical Journal 49: 4.

8. MRI (2002) A Survey Report: Nutritional Problems among Sri Lankan Primary School Children Aged 5-9 years. Medical Research Institute, Colombo, Sri Lanka.

9. Dehghan M, Akhtar-Danesh N, Merchant AT (2005) Review: Childhood obesity, prevalence and prevention. Nutrition Journal 4: 24 .

10. Rathnayake KM, Satchithanantham A, Mahamithawa S, Jayawardana R (2013) Early life predictors of preschool overweight and obesity: a case-control study in Sri Lanka. BMC Public Health 13: 994.

11. Rolland-Cachera MF, Deheeger M, Bellisle F, Sempé M, Guilloud-Bataille M et al. (1984) Adiposity rebound in children: a simple indicator for predicting obesity. American Journal of Clinical Nutrition 39: 129-135.

12. Fung C, Kuhle S, Lu C, Purcell M, Schwartz M, et al. (2012) From "best practice" to "next practice": the effectiveness of school-based health promotion in improving healthy eating and physical activity and preventing childhood obesity. Int J Behav Nutr Phys Act 9: 27

13. Chu NF, Rimm EB, Wang DJ, Liou HS, Sheih S (1998) Clustering of cardiovascular disease risk factors among obese school children: the Taipei children heart study. American Journal of Clinical Nutrition 67: 1141-1146.

14. DeOnis M (2008) The New Who Child Growth Standards. Paediatr Croat 52 (Supl 1): 13-17.

15. WHO (2015) Global Strategy on Diet, Physical Activity, and Health. World Health Organization, Geneva.

16. Vos MB, Welsh J (2010) Childhood Obesity: Update on Predisposing Factors and Prevention Strategies. Curr Gastroenterol Rep 12: 280-287.

17. Maruf FA, Aronu U, Chukwuegbu K, Aronu A (2013) Influence of gender on prevalence of overweight and obesity in Nigerian school children and adolescents. Tanzania Journal of Health Research 15: 1-6.

18. Wickramasinghe VP, Lamabadusuria SP, Cleghorn GJ, Davies PSW (2011) Defining anthropometric cut-off levels related to metabolic risk in a group of Sri Lankan children. Annals of Human Biology 1-7.

19. Ong KKL, Ahmed ML, Emmelt PM, Preece MA, Dunger DB, et al. (2000) Association between postnatal catchup growth and obesity in childhood: prospective cohort study. BMJ 320: 967-971.

20. Dundar C, Oz H (2012) Obesity related factors in Turkish school children. The scientific world journal 2012: 353485

21. Onge MPS, Keller KL, Heymsfield SB (2003) Changes in childhood food consumption pattern: a cause for concern in light of increasing body weights. American Journal of Clinical Nutrition 78: 1068-73

22. Poti MJ, Duffey KJ, Popkin BM (2014) The association of fast food consumption with poor dietary outcomes and obesity among children: is it the fast food or the remainder of the diet? American Journal of Clinical Nutrition 99: 162-71.

23. Epstein LH, Gordy CC, Raynor HA, Beddome M, Kilanowski CK, et al. (2001) 
Increasing fruit and vegetable intake and decreasing fat and sugar intake in families at risk for childhood obesity. Obese Research 9: 171-178

24. Umairah SN, Yahya BT, Datin M, Yusof (2012) Relationship between dietary pattern and body mass index among primary school children. Asian Journal of Clinical Nutrition 4: 142-150.

25. Veldhuis L, Vogel I, Renders CM, Rossem LV, Oenema A, et al. (2012) Behavioral risk factors for overweight in early childhood the 'Be active, eat right' study. International Journal of Behavioral Nutrition and Physical Activity 9: 74.

26. Mushhaq MU, Gull S, Mushtaq K, Shahid U, Shad MA, et al. (2011) Dietary behaviors, physical activity and sedentary lifestyle associated with overweight and obesity, and their socio-demographic correlates, among Pakistani primary school children. International Journal of Behavioral Nutrition and Physical Activity 8: 130 .

27. Ortega RM, Requejo AM, Lopez-Sobaler AM, Quintas ME, Andres P, et al (1998) Difference in the breakfast habits of overweight/obese and normal weight school children. International Journal for Vitamin \& Nutrition Research 68: $125-132$.

28. Bhuiyan MU, Zaman S, Ahmad T (2013) Risk factors associated with overweight and obesity among urbal school children adolescents in Bangladesh: a case control study. BMC Pediatrics 13: 72.

29. Trembley MS, LeBlanc AG, Kho ME, Saunders TJ, Larouche R, et al. (2011) Systematic review of sedentary behaviour and health indicators in school-aged children and youth. International Journal of Behavioral Nutrition and Physical Activity 8: 98.

30. Herman KM, Sabiston CM, Mathieuc M, Tremblay A, Paradise G (2014) sedentary behavior in a cohort of 8- to 10-year-old children at elevated risk of obesity. Prev Med 60: 115-120.
31. Ekelund U, Brage S, Froberg K, Harro M, Anderssen SA, et al. (2006) TV viewing and physical activity are independently associated with metabolic risk in children: the European Youth Heart Study. PLoS Med 3: e488.

32. Guedes DP, Rocha GD, Silva AJRM, Carvalhal IM, Coelho EM (2011) Effects of social and environmental determinants on overweight and obesity among Brazilian school children from a developing region. Rev Panam Salud Publica 30: 295-302.

33. Mozaffari H, Nabaei B (2006) Obesity and related risk factors. Indian J Pediatr 74: 265-267.

34. Dev DA, McBride BA, Fiese BH, Jones BL, Cho H (2013) Risk Factors for Overweight/Obesity in Preschool Children: An Ecological Approach. Child Obesity 9: 399 - 408.

35. Martinez SM, Tschann JM, Greenspan LC, Deardorff J, Penilla C, et al. (2014) Is it time for bed? Short sleep duration increases risk for obesity in Mexican American children, Sleep Medicine 15: 1484-1489.

36. Sekine M, Yamagami T, Handa K, Satio T, Nanri S, et al. (2001) A doseresponse relationship between short sleeping hours and childhood obesity: results of the Toyama birth cohort study. Child Care Health \& Development 28: $163-170$

37. Hui LL, Nelson EAS, Yu LM, Li AM, Fok TF (2003) Risk factors for childhood overweight in 6 to $7 \mathrm{y}$ - old Hong Kong children. International Journal of Obesity 27: 1411-1418.

38. Ishaque A, Ahmad F, Zehra N, Amin H (2012) Frequency of and factors leading to obesity and overweight in school children. J Ayub Med Coll Abbottabad 24 $34-38$

39. Mitchell JA, Mattocks C, Ness AR, Leary SD, Pate RR, et al. (2009) Sedentary behavior and obesity in a large cohort of children. Obesity (Silver Spring) 17: 1596-1602. 